\title{
Dose-Response Hearing Loss for White Noise in the Sprague-Dawley Rat ${ }^{1}$
}

\author{
Michael J. Sullivan $*, \uparrow^{2}$ and Rory B. CONOLly $\dagger^{+3}$ \\ ${ }^{*}$ Kresge Hearing Research Institute, $\dagger$ Toxicology Program, School of Public Health, The University of Michigan, \\ Ann Arbor, Michigan 48109
}

Received October 7, 1986; accepted August 11, 1987

\begin{abstract}
Dose-Response Hearing Loss for White Noise in the Sprague-Dawley Rat. Sullivan, M. J., AND Conolty, R. B. (1988). Fundam. Appl. Toxicol. 10, 109-113. The effect of noise exposure on the inner ear is well documented. However, the sensitivity to noise-induced damage varies with animal species. The purpose of this investigation was to generate a hearing loss doseresponse curve for a 20-day white noise exposure in the Sprague-Dawley rat. Eight male rats were exposed to $110,100,95$ or $85 \mathrm{~dB}$ sound pressure level (SPL) for $6 \mathrm{hr} /$ day, 5 days/week for 4 weeks in a sound-attenuated chamber fitted with a bank of overhead speakers. Controls were placed in an identical chamber without speakers. Four weeks after the exposure period ended, brainstem auditory evoked response (BAER) thresholds were recorded in all rats at 32, 16, 8, 4, 2,1 , and $0.5 \mathrm{kHz}$. Rats were then killed and cochlear tissues were processed for surface preparation. Hair cells were counted. Outer hair cell loss in the organ of Corti was observed in rats exposed to 95,100 , and $110 \mathrm{~dB}$. Summary cytocochleograms were prepared for each rat by graphing the percentage of all hair cells remaining vs the percentage of distance along the basilar membrane as measured from the apex. The summary cytocochleograms were averaged and the area above this curve, corresponding to hair cell loss, was calculated. BAER threshold elevations (dB) were converted into percentage loss overall hearing function. Noise exposure level (dB) and (1) percentage area above the group average summary cytocochleogram and (2) percentage hearing loss were plotted as dose-response curves. Log-probit analysis was used to calculate ED50 noise exposure levels of 117 and $104 \mathrm{~dB}$ (SPL), (1), and (2), respectively. No observable effect level, lowest observable adverse effect level, and frank effect levels are identified. (c) 1988 Society of Toxicology.
\end{abstract}

The use of the rat as an experimental animal in studies of hearing and ototoxicity is increasing. Rats have been used to investigate the effects of toluene (Rebert et al., 1983; Sullivan, 1986; Pryor and Howd, 1987), organotin (Fechter et al., 1986), carbon monoxide (Fechter et al., 1987), aminoglycoside antibiotics (Janssen and Carlisle, 1987; Sullivan, 1986), and halogenated hydrocarbons (Sullivan $e t$ al., unpublished) on hearing. Bio-

\footnotetext{
${ }^{1}$ Supported by the American Petroleum Institute.

${ }^{2}$ Current address: NCASI, 260 Madison Avenue, No. 1105, New York, NY 10016.

${ }^{3}$ Current address: Northrup Services, Inc., Environmental Sciences, 101 Woodman Drive, Suite 12, Dayton, $\mathrm{OH} 45431$.
}

chemical studies (Henley and Schacht, 1987) on inner ear tissues and cochlear blood flow experiments (Hillerdal, 1987) in the rat have been performed. The increasing use of the rat to study hearing indicates the need for more basic studies on how the rat responds to the ototramatic agent: noise. The purpose of this investigation was to characterize the functional and morphological changes associated with noise exposure in Spraguc-Dawley rats and to construct a dose-response curve to quantitate the damage. This dose-response curve can be used to predict damage in the rat at a given noise level as well as serve as a baseline for other studies which are ongoing in our laboratory. The morphological and physiological changes in the rat after noise ex- 


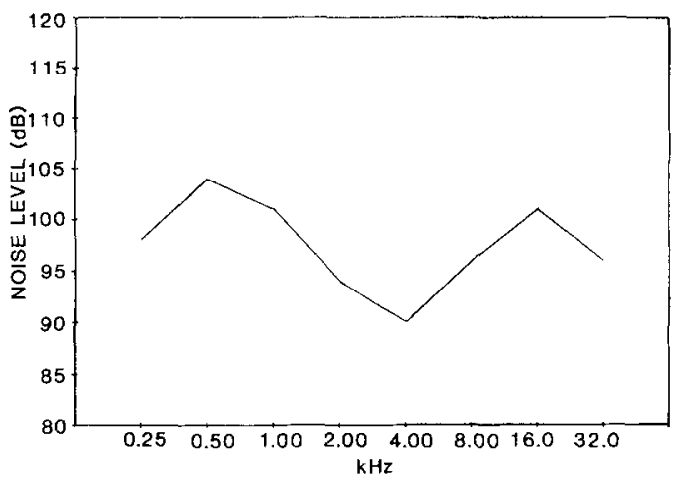

FIG. 1. Spectrum of white noise used in this work. posure provide a basis for comparison of how
other species respond to identical challenges.

\section{METHODS}

Animals. Male Sprague-Dawley rats (175-200 g. Charles River Laboratories, Inc., Portage, MI) were housed four per cage in metal cages and given water and rodent chow (Ralston Purina Co.) ad libitum. The animal quartcrs were maintained at $22^{\circ} \mathrm{C}$ on a $12-\mathrm{hr}$ light/ dark cycle. Rats were acclimatized for 1 week prior to use. Body weights were recorded each day. Background noise levels were below $60 \mathrm{~dB}$ sound pressure level (SPL).

Noise exposure. Eight rats were exposed to broad-band white noise (contains all frequencies) at $110,100,95$, or $85 \mathrm{~dB}$ (SPL) for $6 \mathrm{hr} /$ day, 5 days/week for 4 weeks in a sound-attenuated chamber fitted with a bank of overhead speakers. The noise levels represent the current $\mathrm{AC}$ GIH TLV-TWA (ACGIH, 1986; $85 \mathrm{~dB}$ (SPI) for $8 \mathrm{hr}$ ), the upper limit of the noise generating system $(110 \mathrm{~dB}$ (SPL)) and two intermediate measurements. Rats were directly under the speakers on the chamber floor in plastic tubs with wire mesh tops. Two rats were housed in each tub. The spectrum of the noise is shown in Fig. 1. The noise was produced with a noise generator (Interstellar Research, Model 1) and amplified using a power amplifier (SAE, Model P-10). Measurement of the sound field was made in the plastic tub at the level of the animal's head with the animal removed from the sound field. Measurement was done using a 0.5 -in. condensor microphone (Bruel and Kjaer) and preamplifier coupled to a wave analyzer. Controls were placed in an identical chamber without speakers.

Functional measure. Four weeks after the exposure period ended, brainstcm auditory evoked response (BAER) thresholds were recorded from each rat in a sound-atten- uated box. They were anesthetized with an intraperitoneal injection of ketamine hydrochloride (Ketaset, 50 $\mathrm{mg} / \mathrm{kg}$ ) and xylazine (Rompun, $10 \mathrm{mg} / \mathrm{kg}$ ). Additional doses (one-fourth original dose) were given as needed to maintain a stable state of anesthesia. The recording electrode configuration consisted of three small (26 gauge) hypodermic needles placed under the skin below the ipsilateral right pinna (reference electrode), at the vertex (active electrode), and below the contralateral pinna (ground electrode). The electrodes were connected to an amplifier (Grass, Model P15D; gain, 1000; filter settings, 100-3 kHz). A digital signal averager (Tracor Northern, Model TN-1500) was used for signal averaging. The acoustic stimuli were presented in a closed acoustic system via a 0.5 -in. condenser microphone (Bruel and Kjaer) mated to a brass coupler with an $8.5 \times 0.03-\mathrm{cm}$ Silastic tube inserted into the left external auditory meatus. Thresholds were obtained to tone bursts with a 10 msec duration, 1.0-msec rise time, at $32,16,8,4,2,1$, and $0.5 \mathrm{kHz}$. The stimulus repetition rate was $2 / \mathrm{sec}$. The stimulus intensity was decreased in 5-dB steps, beginning at $90 \mathrm{~dB}$ (SPL). One set of 64 stimuli presentations was given at each intensity and three sets were given to determine threshold. Stimulus intensities were calibrated using a wave analyzer (Hewlett-Packard). The amplitude of wave 4 was followed as the response. The attenuator setting at which a response was last observed was recorded as threshold. BAER data for each animal was plotted as threshold intensity, $\mathrm{dB}$ (SPL) versus stimulus frequency.

Morphological measure. The animals were killed by decapitation, the temporal bones removed, and the auditory hulla opened. Inner ear tissues were fixed by perfusing phosphate-buffered ( $\mathrm{pH} 7.4$ ) $2.5 \%$ glutaraldehyde solution through both the oval and round windows and placing the tissue in a $20-\mathrm{ml}$ glass vial on a $14-\mathrm{in}$. rotor at $12 \mathrm{rpm}$ at a $30^{\circ}$ angle for $1 \mathrm{hr}$. The tissue was then postfixed with phosphate-buffered ( $\mathrm{pH} 7.4) 1 \% \mathrm{OsO}_{4}$ in a similar manner for $30 \mathrm{~min}$. Cochleas were microdissected as described by Hawkins and Johnsson (1976). Individual turns of the organ of Corti were either mounted on glass microscope slides in glycerol or further processed and embedded in Epon-Araldite-DDSA plastic in microscope slide molds (Ted Pella, Inc.). Sensory hair cells were counted under a phase-contrast microscope (Wild, Model M-20) at $50 \times$.

Statistical analysis. Hair cell loss and BAER threshold elevation were used to construct the dose-response curves. Cytocochleograms were made by plotting the percentage of hair cells remaining in each of the four individual rows, millimeter by millimeter, against percentage distance $(\mathrm{mm})$ along the basilar membrane measured from the apex. Summary cytocochleograms were prepared by graphing the total percentage of all hair cells remaining in all four rows against percentage of distance from the apex. Group average summary cytocochleo- 
TABLE 1

Percentage Hair Cell loss and Hearing loss FOR NOISE EXPOSURE LEVELS

\begin{tabular}{ccc} 
& \multicolumn{2}{c}{ Percentage response (SE) } \\
\cline { 2 - 3 } $\begin{array}{c}\text { Dose } \\
\text { dB(SPL)) }\end{array}$ & Hair cell loss & Hearing loss \\
\hline 110 & $18.98(1.62)$ & $21.63(2.31)$ \\
100 & $6.47(1.87)$ & $9.90(1.40)$ \\
95 & $0.63(.27)$ & $7.28(0.63)$ \\
85 & 0 & 0 \\
\hline
\end{tabular}

Note. SE, standard error.

grams (GASC) were made by averaging the percentage of all hair cells remaining for each rat in a treatment group (summary cytocochleogram) and graphing it against percentage distance from the apex. The area above the GASC curve, corresponding to average treatment group hair cell loss and representing the measure of response, was calculated. BAER threshold elevation (dB) for each rat were summed over the seven frequencies tested. This summed level was converted into percentage overall hearing loss by comparing the increase in sound pressure level needed to elicit a response at threshold between treated and control rats. Noise exposure level $(\mathrm{dB})$ and (1) percentage area above the GASC and (2) percentage hearing loss were plotted as dosc-response curves. Logprobit analysis (Litchfield and Wilcoxon, 1949) was used to calculate an ED50 noise exposure level. Frequency specific elevations in BAER thresholds were calculated and compared to hair cell loss. Analysis of variance was used to calculate significance of differences in group responses.

\section{RESULTS}

Functional measures. Control rat BAER thresholds, calculated from eight nonexposed rats, were similar to those reported by Kelly and Masterton (1977) for the Sprague-Dawley rat. Significant elevations in BAER thresholds were measured in the 110-, 100-, and $95-\mathrm{dB}$ exposed rats. BAER thresholds measured in the 85- $\mathrm{dB}$ exposed rats were at control levels. Table 1 lists the percentage response for each treatment group as measured by hearing loss (BAER threshold elevation). Figure 2 shows BAER threshold data from a
$110-\mathrm{dB}$ treated rat and its associated cytocochleogram. Significant threshold elevations were measured at $4,8,16$, and $32 \mathrm{kHz}$.

Morphological measure. Significant hair cell loss was observed in the 110-, 100-, and 95-dB exposed rats. In the $85-\mathrm{dB}$ exposed rats, hair cell loss was no greater than in the controls. In the 95- $\mathrm{dB}$ exposure, the position of the lesion was in the upper portion of the basal turn of the organ of Corti. There was significant outer hair cell loss, but the pattern of loss observed in the higher exposure levels was not evident. For example, in some areas of the organ of Corti, there were a greater number of missing hair cells in the second or third rows than in the first. In the rats exposed to 100 and $110 \mathrm{~dB}$ (SPL), there was consistent
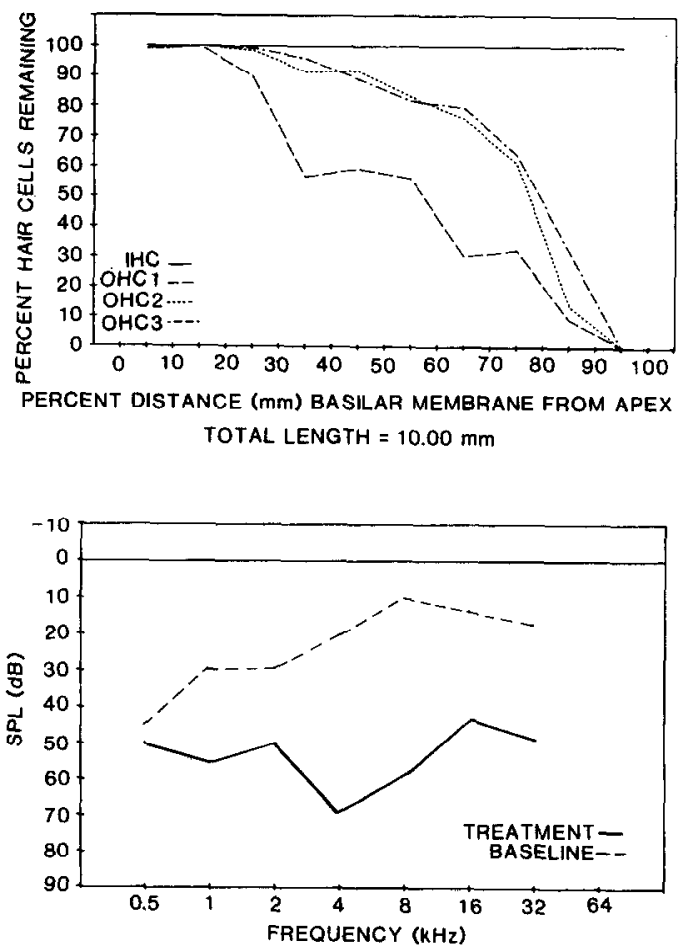

FIG. 2. Cytocochleogram and BAER threshold data from a rat exposed to $110 \mathrm{~dB}$ for $6 \mathrm{hr} /$ day, 5 days/wk for 4 weeks. Graphs are positioned to align the position of the basilar membrane with hearing frequency range. Baseline BAER thresholds are the average of eight controls. 
pattern and position of hair cell loss. The greatest loss occurred in the first row of outer hair cells, followed by the second and then the third. Inner hair cell loss also occurred in regions of complete loss of outer hair cells. usually in the lower basal turn of the cochlea (high frequency region). The position of the lesion was in the basal turn of the organ of Corti and the hair cell loss increased toward the hook. Figure 2 shows a sample cytocochleogram and its associated BAER threshold data from a rat exposed to $110 \mathrm{~dB}$. The positioning of the two graphs is significant. The hearing range of the rat (frequency) is compared with the length of the basilar membrane $(\mathrm{mm})$. BAER threshold elevations are at frequencies which correspond to regions of the organ of Corti where there is significant hair cell loss. Table 1 lists the percentage response for each exposure group as measured by hair cell loss. The amount of outer hair cell loss in the treated groups increased with increasing noise exposure level.

The dose-response curves (probit analysis) generated from hair cell loss or BAER threshold elevation are shown in Fig. 3. The slopes of the two lines are not significantly different, $p>0.05$. However, the calculated ED50's for the hair cell loss and BAER thresholds, 117 and $104 \mathrm{~dB}$, respectively, are significantly different, $p<0.05$.

\section{DISCUSSION}

The four exposure levels produce a range of responses in the rat. Exposure to $85 \mathrm{~dB}$ (SPL) is the no observable effect level (NOEL). The 95-dB (SPL) exposure represents the lowest observed adverse effect level (LOAEL). The two highest exposures of 100 and $110 \mathrm{~dB}$ (SPL) are frank effect levels (FEL). The NOEL in rats is the same as the current ACGIH TLV-TWA of $85 \mathrm{~dB}$ (SPL) for $8 \mathrm{hr}$ (ACGIH, 1986), a level not expected to produce damage to hearing in workers. However, short-term excursions to higher

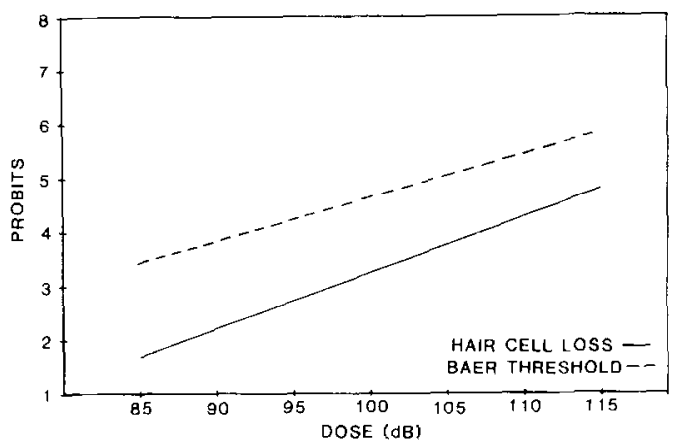

FlG. 3. Dose-response curves for hair cell loss and BAER threshold elevations versus noise level.

noise levels are permitted, $90 \mathrm{~dB}$ for $4 \mathrm{hr}$ or $95 \mathrm{~dB}$ for $2 \mathrm{hr}$, for example. These levels are both below the rat LOAEL.

The ED50's calculated from this $6 \mathrm{hr} /$ day, 5 day/week, 4-week noise exposure are different depending on the parameter of damage used. In the rat, exposure of $117 \mathrm{~dB}$ (SPL) would result in approximately $50 \%$ loss of all hair cells. In terms of overall hearing function, only $104 \mathrm{~dB}$ (SPL) would be needed to result in a $50 \%$ functional loss. The slopes of the two dose-response lines are not significantly different. However, their positions are different due to different ED50's. This indicates that there are functional changes detected as BAER threshold elevations before observed hair cell loss. This may be a consequence of the types of analyses employed to measure hair cell loss and BAER threshold elevations. Hair cell loss is based on a set of criteria that counts the individual cell as present or absent. These criteria do not identify hair cells which may appear normal by light microscopy but may not be functional. It is this population of normal-appearing yet nonfunctional sensory cells which could account for the differences in the two dose-response lines.

Noise exposure thresholds can be obtained from the two dose-response curves. An arbitrary response threshold of $1.0 \%$ above background (control) is used. Exposure thresholds ( $\pm 95 \%$ confidence interval) would be $94 \mathrm{~dB}$ $( \pm 7 \mathrm{~dB})$ as measured by hair cell loss, and 70 
$\mathrm{dB}( \pm 5 \mathrm{~dB})$, measured by BAER threshold elevation. These threshold noise levels are significantly different using Student's $t$ test, $p$ $<0.05$. The estimated threshold for hair cell loss of $94 \mathrm{~dB}$ is similar to the LOAEL of 95 $\mathrm{dB}$, whereas the 70-dB threshold for hearing loss is not. This inconsistency is a function of the sensitivity of the measurements used. A $1 \%$ loss of hair cells can be measured, but a $1 \%$ hearing loss is too small a change to be measured. The actual threshold for hearing loss would be higher than the estimated $70 \mathrm{~dB}$.

It would be useful to be able to compare the sensitivity of the rat to noise-induced injury with the sensitivity of other species, especially the guinea pig in which a great deal of noise exposure research has been done. However, differences in noise exposure profiles (frequency, duration, and $\mathrm{dB}$ level) between exposures reported by other investigators and those used in this study render direct comparisons difficult. One indirect method of comparison between species is the amount of hair cell loss and associated BAER threshold elevation. For example, the data reported here falls within the range of that reported after exposure to aminoglycoside antibiotics in guinea pigs, chinchillas, and monkeys (Stebbins et al., 1981; Sullivan, 1986). The preferred method of comparison would be direct comparison under similar experimental conditions. The protocol described in this report would serve as an excellent means of comparing the sensitivities of several experimental animals to noise-induced hearing loss.

\section{REFERENCES}

American Conference of Governmental Industrial Hygienists (1986). Threshold Limit Values for Chemical
Substances and Physical Agents in the Workroom Environment with Intended Changes for 1986.

FECHTER, L. D., ThORNE, P. R., AND NutTALl, A. L. (1987). Effects of carbon monoxide on cochlear electrophysiology and blood flow. Hear. Res. 27(1), 3745.

FeChTER, L. D., Young, J. S., AND NutTall, A. L. (1986). Trimethyltin ototoxicity: Evidence for a cochlear site of injury. Hear. Res. 23(3), 275-282.

HAWKINS, J. E., JR., AND JOHNSSON, L.-G. (1976). Microdissection and surface preparation of the inner ear. In Handbook of Auditory and Vestibular Research Methods (C. A. Smith, and J. A. Vernon, Eds.), pp. 551. Thomas, Springfield, IL.

HENLEY, C., AND SCHACHT, J. (1987). Inhibition of Ornithine Decarboxylase by Aminoglycoside Antibiotics. Presentation at 1987 mid-winter meeting of Association for Research in Otolaryngology.

Hillerdal, M. (1987). Cochlear blood flow in the rat. A methodological evaluation of the microsphere method. Hear. Res. 27(1), 27-35.

JANSSEN, R., AND CARLISLE, L. (1987). Auditory Physiology and Morphology of Hooded Rats: FrequencySpecific Effects of Kanamycin. Presentation at 1987 mid-winter meeting of the Association for Research in Otolaryngology.

KELLY, J. B., AND MASTERTON, B. (1977). Auditory sensitivity of the albino rat. J. Comp. Physiol. Psych. 91, 930-936.

LITCHFIELD, J. T., AND WILCOXON, F. (1949). A simplified method of evaluating dose-response experiments. J. Pharmacol. Exper. Therap. 96, 99-113.

Sullivan, M. J. (1986). Ototoxicity of Toluene in Rats. Doctoral thesis, University Microfilms, Inc., Ann Arbor, MI.

Sullivan, M. J., Rarey, K. E., and Conolly, R. B., The Ototoxicity of Chloroform, 1,2-Dichloroethane and Carbon-Tetrachloride in Rats, unpublished.

Stebiins, W. C., McGinn, C. S., Fertora, M., Moody, D. B., Prosen, C. A., and Serafin, V. V. (1981). Animal models in the study of ototoxic hearing loss. In Aminoglycoside Ototoxicity (S. A. Lerner, G. L. Matz, and J. E. Hawkins, Eds.), pp. 5-26. Little, Brown, Boston. 